\title{
Optimization and Validation of a Method using SPE and LC-APCI-MS/MS for Determination of Pharmaceuticals in Surface and Public Supply Water
}

\author{
Liziane V. Cardoso, Débora Tomasini, Maicon R. F. Sampaio, Sergiane S. Caldas, \\ Natiele Kleemann, Ednei G. Primel and Fabio F. Gonçalves*
}

Programa de Graduação em Tecnologia e Química Ambiental, Universidade Federal do Rio Grande (FURG), 96201-900 Rio Grande-RS, Brazil

\begin{abstract}
Neste trabalho, foi desenvolvido e validado um método analítico baseado na extração em fase sólida (SPE) e cromatografia líquida acoplada a espectrometria de massas em tandem (LC-APCI-MS/MS) para a determinação e confirmação de cinco fármacos em amostras de água. Os limites de detecção (LOD) variaram de 0,053 a $0,53 \mu \mathrm{L} \mathrm{L}^{-1}$ e os limites de quantificação (LOQ) de 0,16 a $1,6 \mu \mathrm{g} \mathrm{L}^{-1}$. Foi obtida boa linearidade com $r>0,99$ para todos os compostos. As recuperações dos compostos variaram de 70 a $120 \%$, com desvios padrão relativos (RSD) menores que $20 \%$ para todos. Através do monitoramento de reações múltiplas (MRM), foram selecionadas duas transições diferentes íon precursor-íon produto para cada fármaco.
\end{abstract}

In this work, an analytical method based on solid phase extraction (SPE) and liquid chromatography tandem mass spectrometry (LC-APCI-MS/MS) was developed and validated for the determination and confirmation of five pharmaceuticals in water samples. The limits of detection (LOD) ranged from 0.053 to $0.53 \mu \mathrm{g} \mathrm{L}^{-1}$ and the limits of quantification (LOQ) from 0.16 to $1.6 \mu \mathrm{g} \mathrm{L} \mathrm{L}^{-1}$. Good linearity was obtained with $\mathrm{r}>0.99$ for all compounds. The recoveries of the compounds ranged from 70 to $120 \%$ with relative standard deviations (RSD) below $20 \%$ for all. Through multiple reactions monitoring (MRM) two different transitions, precursor ion-product ion, were selected for each pharmaceutical.

Keywords: method validation, SPE, LC-APCI-MS/MS, emergent contaminants

\section{Introduction}

In recent years, there has been a growing interest in the determination of emerging contaminants. Since these are not covered by existing water quality regulatory bodies, the focus of environmental analysis has shifted from the classic contaminants such as persistent organic pollutants, towards the "emergent" contaminants detected recently in many environmental samples. ${ }^{1,2}$ There is an emerging environmental concern on pharmaceuticals which represent a group of chemicals widely used in both human and veterinary medicine. They can enter the environment as unique compounds or metabolites, conjugates, or both. Drugs have been found in several water samples at levels of $n g \mathrm{~L}^{-1}$ and $\mu \mathrm{g} \mathrm{L}^{-1}$. 2,3

In the last decade, interest in the determination of drugs, cosmetics and personal care products (by the Pharmaceuticals and Personal Care Products as Pollutants,

\footnotetext{
*e-mail: fabio.ferreira@pq.cnpq.br
}

PPCPs) has been increasingly worrisome because of their pseudo persistent properties and their potential harmful effects to humans and to the environment. ${ }^{3}$ The main sources of pharmaceutical products in the environment are wastewater from hospitals, homes and pharmaceutical industries, aquaculture, livestock and the disposal of unused or expired medicinal products. ${ }^{1,2}$ Wastewater treatment plants (WWTP) are not designed to completely remove the majority of pharmaceutical products, consequently, these are released into natural waters. ${ }^{4,5}$ In addition, pharmaceuticals can eventually reach drinking water due to their high water solubility and low degradability. ${ }^{4}$

It is possible that continued low levels of pharmaceuticals in surface waters lead to subtle changes in organisms, and these effects may become evident only over longer periods of time..$^{5}$ Antibiotics, followed by steroid compounds, analgesics and anti-inflammatories are the most widely studied classes of pharmaceutical products. ${ }^{6}$ Antibiotics are one of the most important groups in medicine and have been detected in different types of aqueous matrices, 
for example, waste water, surface and groundwater water and drinking water. ${ }^{7}$ There is a growing concern about their presence, persistence and destination in the environment because low levels of antibiotics can promote the proliferation of resistant bacteria.

The pharmaceutical atenolol is a beta-blocker which was discovered in 1958. This class has received enormous clinical attention because of its effectiveness in the treatment of hypertension and heart diseases. Atenolol is currently marketed under the trade name Atenol at doses of 25,50 and $100 \mathrm{mg}$. It is in $34^{\text {th }}$ place in the ranking of the top-selling drugs in the world. ${ }^{8}$ Diclofenac is a anti-inflammatory which was developed in the 1960's. It is among the most widely used pharmacologic agents and has analgesic, antipyretic and anti-inflammatory action. Diclofenac is the pharmaceutical most frequently detected in the water cycle in Europe. ${ }^{9}$ Some of its trade names are Cataflan ${ }^{\circledR}$, Poltax Flan ${ }^{\circledR}$, Pencivet Plus ${ }^{\circledR}$. Caffeine belongs to the group of chemical substances called xanthines. It is a mild stimulant of the nervous system and the psychoactive drug most used in the world. It is present in soft drinks, coffee, tea, cocoa, chocolate and many pharmaceuticals. Caffeine is included in the list from the United States Environmental Protection Agency (U.S.-EPA) of the chemical compounds produced in greater volume in the world ${ }^{8,10}$ Sulfamethoxazole is an antibiotic that belongs to the sulfonamide group which was the first effective chemotherapeutic agent in the prevention and cure of bacterial infections. The release of antibiotics in aquatic compartments can lead to water contamination and enhance the bacterial resistance to antibiotics. The penicillin emergence decreased the sulfonamides use. But the association of the sulfamethoxazole with the trimethoprim, in the mid-1970, expanded its use. ${ }^{8,11}$ Fluoxetine was introduced in the market in the 1980's. It is used in the treatment of depression, nervous bulimia, premenstrual disorder, panic disorder and posttraumatic stress treatments. Currently, 10 to $15 \%$ of prescriptions in the USA refer to drugs designed to alter mental processes. ${ }^{8,12}$

The selection of the analytes included in this study was based on their broad use in human and veterinary medicine. Moreover, these pharmaceuticals are part of the National List of Essential Medicines (RENAME).

The drugs are present in water samples at a low concentration $^{7}$ and require the use of techniques of extraction and preconcentration for the determination of these compounds. The classical liquid-liquid extraction (LLE) has been replaced largely in laboratories by solid phase extraction (SPE). Therefore, it has been the most preferred sample preparation technique to extract the pharmaceutical compounds from water samples. ${ }^{13} \mathrm{ENV}+$,
Oasis HLB, Oasis MAXSPE, Oasis MCX, Strata-X, C18 LiChrolut and LiChrolut EN proved to be the most effective for preconcentration and clean-up of drugs in aqueous samples. ${ }^{14}$ Cartridges with polymeric phases have an equilibrated hydrophilic-lipophilic balance suitable to extract a wide range of polar and nonpolar compounds. However, besides the compounds of interest, these materials are able to extract other substances within wide range of pKa values. ${ }^{15}$

In the last decade, high performance liquid chromatography (HPLC) combined with tandem mass spectrometry (MS/MS) has become the analytic technique of choice for the determination of polar environmental pollutants due to its selectivity and sensitivity. ${ }^{5,14}$

The developed method involves sample pre-treatment by SPE followed by the use of the liquid chromatographytandem mass spectrometry method with atmospheric pressure chemical ionization (LC-APCI-MS/MS) for the determination. The performance of the method was evaluated by estimation of the linearity, sensitivity, repeatability, reproducibility and matrix effects.

Finally, the method was successfully applied to analysis of five different classes of therapeutic pharmaceuticals in surface and drinking water samples. Samples were taken at the CORSAN (Companhia Riograndence de Saneamento), the water treatment station in the Rio Grande City (Rio Grande do Sul State, Brazil) and the pharmaceuticals under study were: sulfamethoxazole, diclofenac, atenolol, fluoxetine and caffeine.

\section{Experimental}

\section{Chemicals and reagents}

High purity (> 90\%) analytical standards of sulfamethoxazole (sulfonamide antibiotic), diclofenac (analgoantipyretics), atenolol ( $\beta$-blocker), fluoxetine (antidepressant) and caffeine (stimulant) were provided by Fiocruz (Fundação Oswaldo Cruz, Rio de Janeiro-RJ, Brazil). The chemical structure and physicochemical properties of the analyzed pharmaceuticals can be observed in Table 1.

The individual standard solutions were prepared in methanol at the concentration of $1000 \mu \mathrm{g} \mathrm{mL}^{-1}$. The working standard solutions were prepared at $100 \mu \mathrm{g} \mathrm{mL}^{-1}$ by mixing the appropriate amounts of the individual standard solutions and dilution with methanol. All solutions were preserved at $-18^{\circ} \mathrm{C}$.

All solvents used were HPLC grade from by Mallinckrodt (Phillisburg, NJ, USA), and all the other reagents were of analytical grade. Ultrapure water was obtained by 
Table 1. Chemical structure and physicochemical properties of the pharmaceuticals

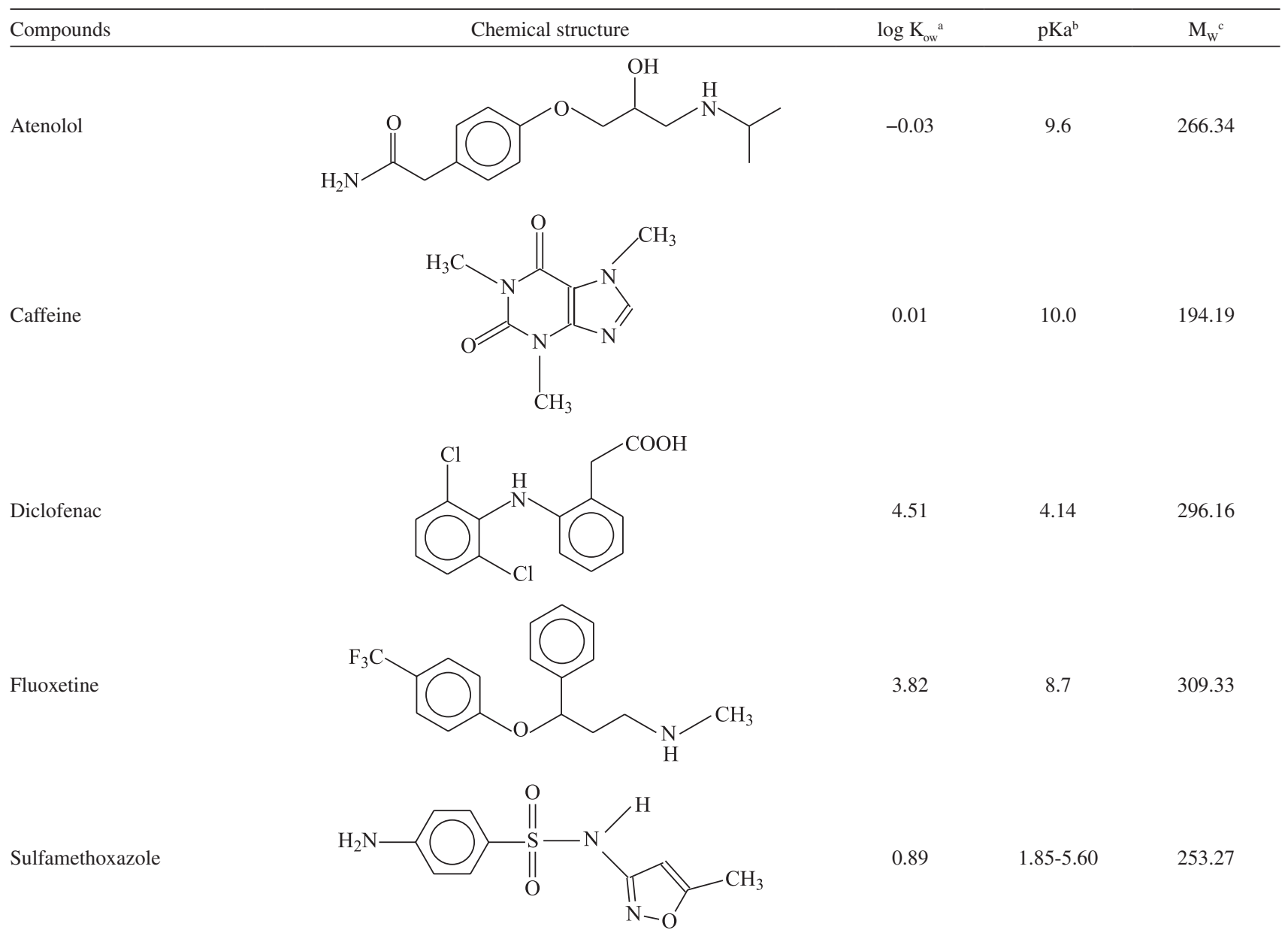

${ }^{\mathrm{a}} \log \mathrm{K}_{\mathrm{ow}}$, octanol-water partition coefficient; ${ }^{\mathrm{b}} \mathrm{pKa}$, acid constant; ${ }^{\mathrm{c}} \mathrm{M}_{\mathrm{W}}$, molecular weight

Direct-Q UV3 ${ }^{\circledR}$ water purification system (Millipore, Bedford, MA, USA). The SPE extraction with the following adsorbents was evaluated: ChromabondC18-Ec (octadecyl modified silica phase), Accubond II ODS-C18 (octadecylsilane), Strata-X (copolymer of styrene-divinylbenzene with modified surface), Strata SDB-L (styrene-divinylbenzene Polymer) all with $500 \mathrm{mg}$ of phase in cartridges. The adsorbents were obtained respectively from Macherey-Nagel, Agilent Technologies, and the other two polymers from Phenomenex (Torrance, CA, USA).

\section{SPE procedure}

The isolation of the target pharmaceutical from water samples was performed using a SPE procedure. The method was developed and optimized using tap water which was filtered through cellulose membranes $(0.45 \mu \mathrm{m}$ pore size $)$ and further enriched with working standard solution to produce a concentration of $1.0 \mu \mathrm{g} \mathrm{mL}^{-1}$ for each analyte in the final extract. The analytes were extracted by SPE using Strata-X cartridges with $500 \mathrm{mg}$ of polymeric sorbent with average particle size of $33 \mu \mathrm{m}$. Cartridges were conditioned with $2 \times 3 \mathrm{~mL}$ of methanol and $2 \times 3 \mathrm{ml}$ of ultrapure water. After the conditioning step, $250 \mathrm{~mL}$ of water sample were run through the cartridges with a flow rate of $3 \mathrm{~mL} \mathrm{~min}^{-1}$. After that, the analytes were eluted with $2 \times 2 \mathrm{~mL}$ of methanol into the autosampler vial and analysed by LC-MS/MS.

\section{Sampling}

Samples were taken at the CORSAN water treatment station in the Rio Grande City (Rio Grande do Sul State, Brazil) (Latitude $-32^{\circ} 02^{\prime} 06$ " Longitude $-52^{\circ} 05^{\prime} 55^{\prime \prime}$ ), during three months (October, November and December) of 2010. Two different samples were collected, a surface water sample, directly from the point of entry of the São Gonçalo Channel, and the other one after the water treatment step, the exit point where the water enters the public water supply system. The total number of samples was six. 
Samples were collected directly in $1 \mathrm{~L}$ amber glass bottles in each sampling site. These bottles had been cleaned prior to sampling by rinsing them three times in the water to be sampled. The samples were filtered and aliquots subjected to the SPE procedure for extraction of analytes and the cartridges were wrapped in aluminum foil and stored in a freezer at $-18{ }^{\circ} \mathrm{C}$ until further analysis.

\section{$L C-A P C I-M S / M S$}

Liquid chromatography with mass spectrometric detection was performed in a Waters Alliance 2695 separations Module fitted with an autosampler, a membrane degasser and a quaternary pump. Mass spectrometry was performed on a Micromass Quattro Micro API with an APCI interface. The LC (liquid chromatography) separation was carried out in an XTerra analytical column $(50 \times 3 \mathrm{~mm}$, i.d. $3.5 \mu \mathrm{m})$ (Waters, Milford, MA, USA). Analytical instrument control, data acquisition and treatment were performed by the software Masslynx version 4.1, 2005 (Waters, Milford, MA, USA). A sample volume of $2 \mu \mathrm{L}$ was injected by an autosampler. The mobile phase was methanol:water $(70: 30, \mathrm{v} / \mathrm{v})$, acidified with $0.1 \%$ formic acid at a constant flow rate of $0.2 \mathrm{~mL} \mathrm{~min}^{-1}$.

Parameters were optimized by continuous infusion of a standard solution (1000 $\left.\mu \mathrm{g} \mathrm{L} \mathrm{L}^{-1}\right)$ via a syringe pump at $10 \mu \mathrm{L} \mathrm{min}{ }^{-1}$ flow rate. Ionization of the compounds was studied by using APCI interface in the positive ionization (PI) mode. The mass spectrometer was operated in MRM (multiple reaction monitoring) mode. Typical interface conditions were optimized for maximum intensity of the precursor ions as follows: capillary voltage $3.5 \mathrm{kV}$; nebulizer and desolvation (drying gas) flows were set at 350 and $150 \mathrm{~L} \mathrm{~h}^{-1}$, respectively; source block and desolvation temperatures were 120 and $350^{\circ} \mathrm{C}$, respectively. Nitrogen was used as nebulizing, desolvation and cone gas, and argon was used as collision gas.

\section{Analytical parameters}

The performance characteristics of the LC-APCI-MS/MS method were established by a validation procedure and use of standard solutions and spiked samples. Linearity, precision, accuracy (recovery), limits of detection and quantification were evaluated. The linearity was evaluated by using various concentrations of pharmaceuticals ranging from 1 to $1000 \mu \mathrm{g} \mathrm{L}^{-1}$ by LC-APCI-MS/MS, with three replicate injections per concentration. The linearity was assessed by linear regression equation $(y=a x+b)$.

In this study, the limits of detection (LOD) and of quantification (LOQ) of the instrument (called $\mathrm{LOD}_{\mathrm{i}}$ and
$\mathrm{LOQ}_{\mathrm{i}}$, respectively) for each compound was estimated from the signal-noise ratio (SNR) by the visual method, considering at least 3 and 10 times the ratio of the signal by the baseline (noise), respectively. The instrumental limits were obtained by external standardization with the preparation of analytical solutions of different concentrations in methanol.

The limits of detection and quantification of the method ( $\mathrm{LOD}_{\mathrm{m}}$ and $\mathrm{LOQ}_{\mathrm{m}}$, respectively) were obtained by dividing the pre-concentration factor of 62.5 by the limit of quantification. The practical detection limits were observed when the blank matrix extract was fortified at the level of the limit of quantification of each compound and obtained recoveries exceeding $70 \%$.

The precision of the method was evaluated in terms of repeatability $\left(\mathrm{RSD}_{\mathrm{r}}\right)$ and intermediate precision $\left(\mathrm{RSD}_{\mathrm{ip}}\right)$ and expressed as relative standard deviation (RSD). The precision in terms of repeatability was obtained by carrying out the extraction and analysis of fortified samples in three different levels considering the 62.5-fold SPE preconcentration step. Each fortification level was extracted in three replicates and injected three times. The intermediate precision test was performed on different days, but employing the same methodology as the repetitivity.

The accuracy of the method was investigated through mean recoveries. Recovery was determined by adding known amounts of the reference substance at the beginning of the process. Blank water samples spiked with all pharmaceuticals were extracted by applying the SPE method described above. Analyses were carried out in three replicates at three levels for LC-APCI-MS/MS. The accuracy of the method must be in the range of 70-120\% at all concentrations with RSD $<20 \% .^{16}$

\section{Results and Discussion}

\section{Optimization of LC-APCI-MS/MS parameters}

With the purpose of finding the optimal instrumental conditions for unambiguous identification of analyte residues in real samples, preliminary LC-APCI-MS/MS experiments with the mobile phase as methanol:water acidified with $0.1 \%$ formic acid and $0.1 \%$ acetic acid at a constant flow rate of $0.2 \mathrm{~mL} \mathrm{~min}^{-1}$ were performed.

Acetic and formic acids were tested in this study. Formic acid was chosen because it helps in ionization in positive mode and has a pKa less than of the acetic acid and dissociates easily releasing $\mathrm{H}^{+}$. The tuning of the instrument was performed for each drug using a standard solution prepared at $1000 \mu \mathrm{g} \mathrm{mL}^{-1}$. 
Table 2. Results of the optimized parameters for the compounds analyzed by LC-APCI-MS/MS in the positive mode

\begin{tabular}{|c|c|c|c|c|c|}
\hline Pharmaceutical & Molar mass & $\begin{array}{c}\text { Transition }(\mathrm{m} / \mathrm{z}) \\
\text { Precursor ion } \\
\text { Product ion }\end{array}$ & Collision energy / eV & Cone voltagem / V & $\mathrm{t}_{\mathrm{R}} / \min$ \\
\hline \multirow[t]{2}{*}{ Atenolol } & 266 & $267.3>145.0$ & 27 & 35 & 1.00 \\
\hline & & $267.3>190.2$ & 25 & 25 & \\
\hline \multirow[t]{2}{*}{ Fluoxetine } & 309 & $310.2>43.4$ & 9.0 & 30 & 1.14 \\
\hline & & $310.2>145.1$ & 10 & 20 & \\
\hline \multirow[t]{2}{*}{ Sulfamethoxazole } & 253 & $254.4>107.9$ & 15 & 15 & 1.49 \\
\hline & & $254.4>91.7$ & 15 & 15 & \\
\hline \multirow[t]{2}{*}{ Caffeine } & 194 & $195.1>110.0$ & 60 & 25 & 1.57 \\
\hline & & $195.1>136.0$ & 60 & 25 & \\
\hline \multirow[t]{2}{*}{ Diclofenac } & 296 & $297.1>214.1$ & 30 & 30 & 4.98 \\
\hline & & $297.1>250.1$ & 15 & 30 & \\
\hline
\end{tabular}

For each analyte, mass spectra from $\mathrm{m} / \mathrm{z}, 50$ to 350 were recorded in both ionization modes. The most abundant ions in MS spectra were subjected to further MS ${ }^{\mathrm{n}}$ fragmentations. Analytes were determined by LC-APCI-MS/MS in positive mode $[\mathrm{M}+\mathrm{H}]^{+}$by multiple reaction monitoring (MRM). The precursor ions and fragmentation reactions were selected for quantification of every analyte in the screening method (Table 2).

A MRM chromatogram obtained from the analysis of a standard mixture of the five compounds can be observed in Figure 1, which shows the transitions of the compounds used for quantification. Methanol and water were chosen as mobile phases for the separation of drugs. In general these compounds are weakly retained on reverse phase chromatography ${ }^{17}$ The chromatogram shows that some analytes have the same retention time. However, the technique using LC-MS/MS can solve the problems regarding chromatographic resolution by using the higher selectivity of the mass spectrometer when operating in the MRM mode.

\section{Optimization of SPE procedure}

Sample preparation procedure is an important step in developing the method. The choice of sorbent is a key point in solid-phase extraction because it can affect the method performance, for example selectivity, affinity and capacity. ${ }^{18}$ The selected compounds in this study have different physicochemical properties, varying from acidic to basic and from high to low polarity. This complicates the choice of the most appropriate SPE sorbent.

A study was carried out on the most relevant parameters that affect the recovery of target compounds. First of all, the extraction efficiency of four cartridges was tested using tap water from the laboratory when the study was performed,
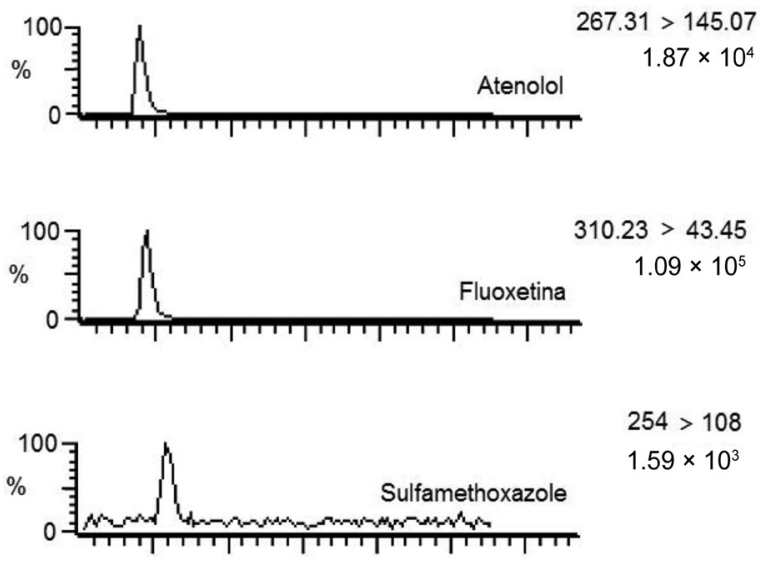

$254>108$

$1.59 \times 10^{3}$

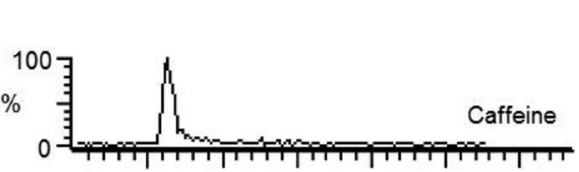

$195>110$

$2.97 \times 10^{3}$

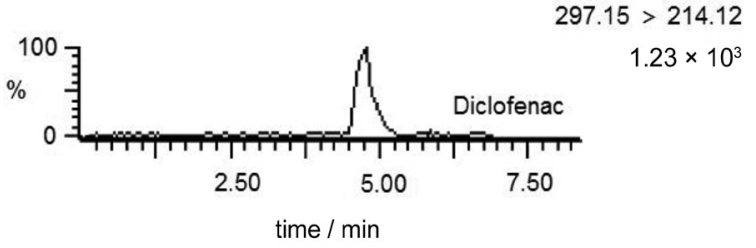

Figure 1. LC-MS/MS chromatograms obtained for pharmaceuticals.

spiked with the analytes. The used cartridges were ChromabondC18-Ec, Accubond II ODS-C18, Strata-X and Strata SDB-L (Figure 2). As methanol seems to be an efficient solvent for the elution of polar contaminants from different SPE cartridges, it was chosen for elution when evaluating the SPE process. ${ }^{7}$

The Strata-X cartridge and Strata SDB-L, both with polymeric adsorbent, provided recoveries in the range of $70-120 \%$. The Strata-X was chosen because 
it is cheaper. The Strata-X SPE cartridge selected has a surface-modified styrene skeleton with a pyrrolidone group, whose retention mechanisms are hydrophobic, hydrogen-bonding and aromatic. This sorbent is used for reversed-phase extraction of acidic, basic and neutral compounds. ${ }^{18}$

Three elution solvents (acetonitrile, methanol and acetone) were evaluated (Figure 3). Recoveries were better when eluting with methanol; so, this solvent was selected for elution $(4 \mathrm{~mL})$.

After that, different volumes of the solvent in question in the following amounts: 1, 2, 4, 6 and $8 \mathrm{~mL}$ were evaluated. It is seen in Figure 4 that the volume of $4 \mathrm{~mL}$ showed a better recovery for all the five studied drugs and this was defined as the volume to be used.

\section{Analytical method validation}

For the construction of standard curves, a mixture of standard solution containing all five analytes from the
LOQ of each compound (50-500 $\mu \mathrm{g} \mathrm{L^{-1 }}$ for caffeine and sulfamethoxazole; $10-100 \mu \mathrm{g} \mathrm{L}^{-1}$ for atenolol and fluoxetine; $100-1000 \mu \mathrm{g} \mathrm{L} \mathrm{L}^{-1}$ for diclofenac) was prepared by the dilution in methanol. To evaluate the matrix effect, curves were also prepared in blank matrix extract for all compounds. Each solution was injected three times and the linear regression data were obtained using the software (Waters MassLynx 4.0) equipment. From these data, the correlation coefficient ( $\mathrm{r}$ ) was evaluated thereby achieving the linearity of the instrument and method. The results (Table 3) did not show a significant deviation in linearity, which means a correlation coefficient of $r>0.99$.

Taking into consideration the pre-concentration factor, the LODs for the method varied from 0.053 to $0.53 \mu \mathrm{g} \mathrm{L}-1$ whereas the intervals of the LOQs changed from 0.16 to $1.6 \mu \mathrm{g} \mathrm{L}^{-1}$.

The $\mathrm{RSD}_{\mathrm{r}}$ and $\mathrm{RSD}_{\mathrm{ip}}$ for instrument $(\mathrm{n}=3$ ) were evaluated with the same concentration levels of standard curves of the pharmaceutical. The values of RSD (\%) of all areas of the injections were: $2.5 \%$ for caffeine, $4.5 \%$ for

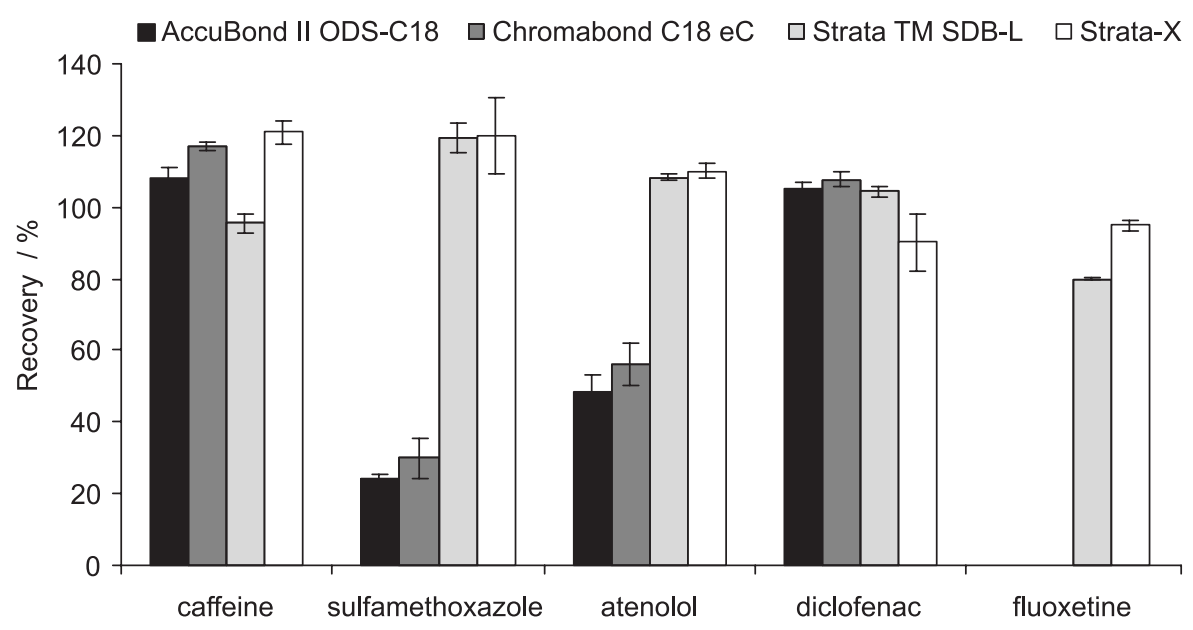

Figure 2. Recoveries comparing different adsorbent materials, the error bars indicate RSD (\%).

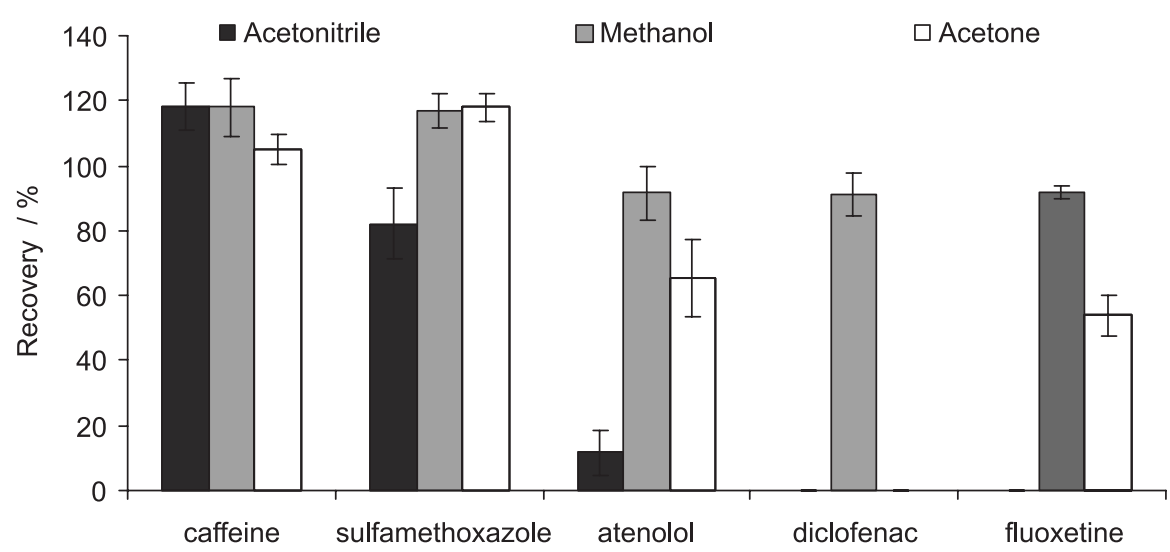

Figure 3. Recoveries comparing different elution solvents, the error bars indicate RSD (\%). 


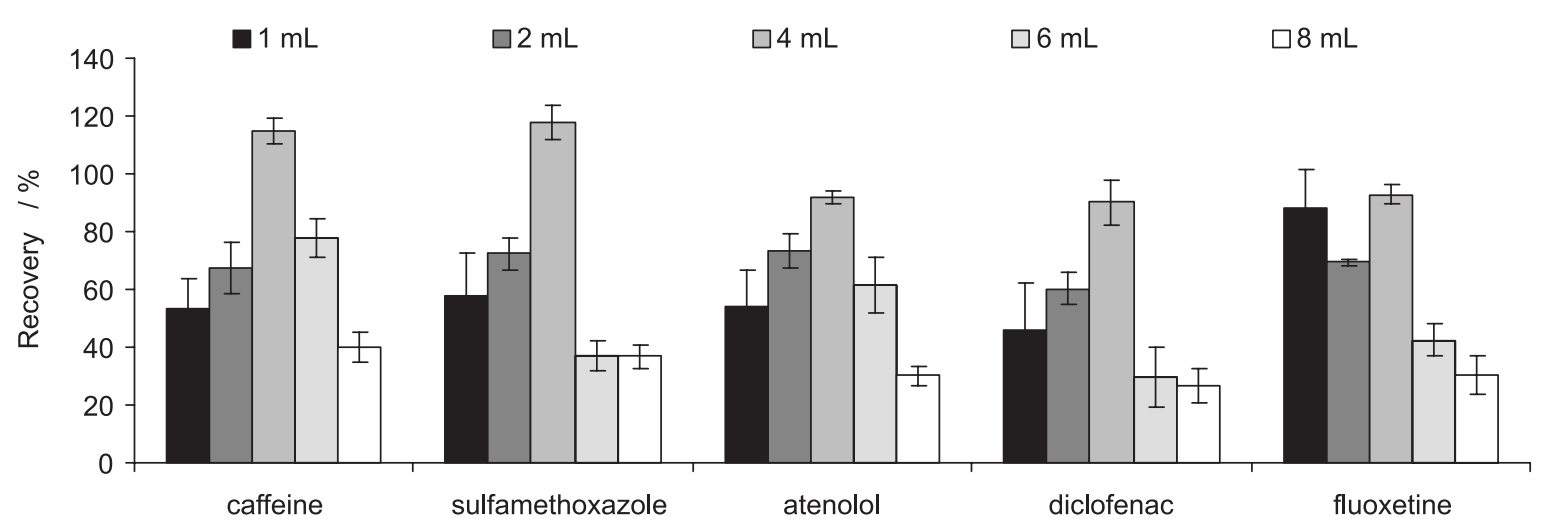

Figure 4. Recoveries comparing different volumes of elution solvent, the error bars indicate RSD (\%).

Table 3. Results obtained for the calibration of the drugs, using the SPE system LC-APCI-MS/MS

\begin{tabular}{|c|c|c|c|}
\hline Pharmaceutical & $\begin{array}{l}\text { Analytical curve in the solvent } \\
r\end{array}$ & $\begin{array}{l}\text { Analytical curve in the matrix } \\
\text { (supply water) } \\
\text { r }\end{array}$ & $\begin{array}{l}\text { Analytic curve in the matrix } \\
\text { (surface water) } \\
\text { r }\end{array}$ \\
\hline Caffeine & $\begin{array}{c}\mathrm{y}=1.310^{6} \mathrm{x}-2.410^{3} \\
0.9991\end{array}$ & $\begin{array}{c}y=1.010^{6} x+6.110^{4} \\
0.9986\end{array}$ & $\begin{array}{c}y=1.410^{6} x+6.210^{4} \\
0.9907\end{array}$ \\
\hline Fluoxetine & $\begin{array}{c}y=5.110^{7} x-4.810^{5} \\
0.9952\end{array}$ & $\begin{array}{c}y=2.010^{7} x-3.610^{4} \\
0.9972\end{array}$ & $\begin{array}{c}y=2.210^{7} x-5.010^{4} \\
0.9955\end{array}$ \\
\hline Diclofenac & $\begin{array}{c}y=3.310^{5} x+1.610^{4} \\
0.9998\end{array}$ & $\begin{array}{c}y=3.210^{5} x+1.910^{4} \\
0.9981\end{array}$ & $\begin{array}{c}y=3.610^{5} x+1.210^{4} \\
0.9995\end{array}$ \\
\hline Atenolol & $\begin{array}{c}y=3.310^{7} x-9.110^{4} \\
0.9982\end{array}$ & $\begin{array}{c}y=2.210^{7} x+1.910^{4} \\
0.9960\end{array}$ & $\begin{array}{c}y=3.210^{7} x-1.010^{5} \\
0.9961\end{array}$ \\
\hline Sulfamethoxazole & $\begin{array}{c}y=6.410^{5} x+2.110^{4} \\
0.9979\end{array}$ & $\begin{array}{c}y=6.310^{5} x+4.510^{4} \\
0.9924\end{array}$ & $\begin{array}{c}y=8.610^{5} x+6.210^{4} \\
0.9990\end{array}$ \\
\hline
\end{tabular}

fluoxetine, $1.1 \%$ for atenolol, $9.5 \%$ for sulfamethoxazole and $1.9 \%$ for diclofenac. ANVISA (Agência Nacional de Vigilância Sanitária) ${ }^{19}$ and DG SANCO (Directorate General for Health \& Consumers - European Commission) ${ }^{20}$ recommend for the precision a RSD $\leq 20 \%$. The values of RSD for the studies of $\mathrm{RSD}_{\mathrm{r}}$ and $\mathrm{RSD}_{\mathrm{ip}}$ of the method were in the range from 0.32 to $13.85 \%$ and 0.1 to $8 \%$, respectively. The accuracy was expressed by the recovery and ranged from 91 to $118 \%$ for caffeine and sulfamethoxazole which were evaluated in the $0.8,4.0$ and $8.0 \mu \mathrm{g} \mathrm{L} \mathrm{L}^{-1}$ fortification levels. The recovery ranged from 76 to $120 \%$ for fluoxetine and atenolol which were evaluated in the $0.16,0.8$ and $1.0 \mu \mathrm{g} \mathrm{L}-1$ fortification levels. For diclofenac, the recovery was evaluated in the $1.6,8.0$ and $16.0 \mu \mathrm{g} \mathrm{L}^{-1}$ fortification levels ranging from 78 to $97 \%$.

\section{Matrix effects}

Co-eluting matrix compounds can affect the process of ionization of the analyte leading to a signal improvement or signal suppression, known as matrix effect. The matrix effect can result in loss in the accuracy, precision, sensitivity and reproducibility, leading to incorrect quantification of the samples, as has been widely reported. ${ }^{5,21,22}$
Different behaviors are reported in the literature when using electrospray ionization (ESI) or atmospheric pressure chemical ionization (APCI) sources. Many authors observed signal suppression in both ESI and APCI sources and most of them found that the effect is lower in APCI. A signal enhancement in APCI was observed, especially in the presence of high percentages of organic modifier in the mobile phase. ${ }^{23}$

In this work the validation study includes assessment of the matrix effect concerning the analysis of surface and supply water samples. A comparison between the analytical curves of the analytical solutions in methanol and analytical solutions in the extract obtained by SPE was carried out. The calculation were made using equation 1. Matrix effects were deemed low for a range of signal suppression/enhancement $-20 \%<\mathrm{C} \%<20 \%$, medium for the ranges $-50 \%<\mathrm{C} \%<-20 \%$ or $20 \%>\mathrm{C} \%>50 \%$ and high for the ranges $\mathrm{C} \%<-50 \%$ or $\mathrm{C} \%>50 \%{ }^{24}$

Matrix effect $\%=\frac{\text { slope }\left(X_{1}\right)-\text { slope }\left(X_{2}\right)}{\text { slope }\left(X_{2}\right)} 100$

where $X_{1}=$ slope of the curve obtained by injection of the analytical solutions of each pharmaceutical prepared in 


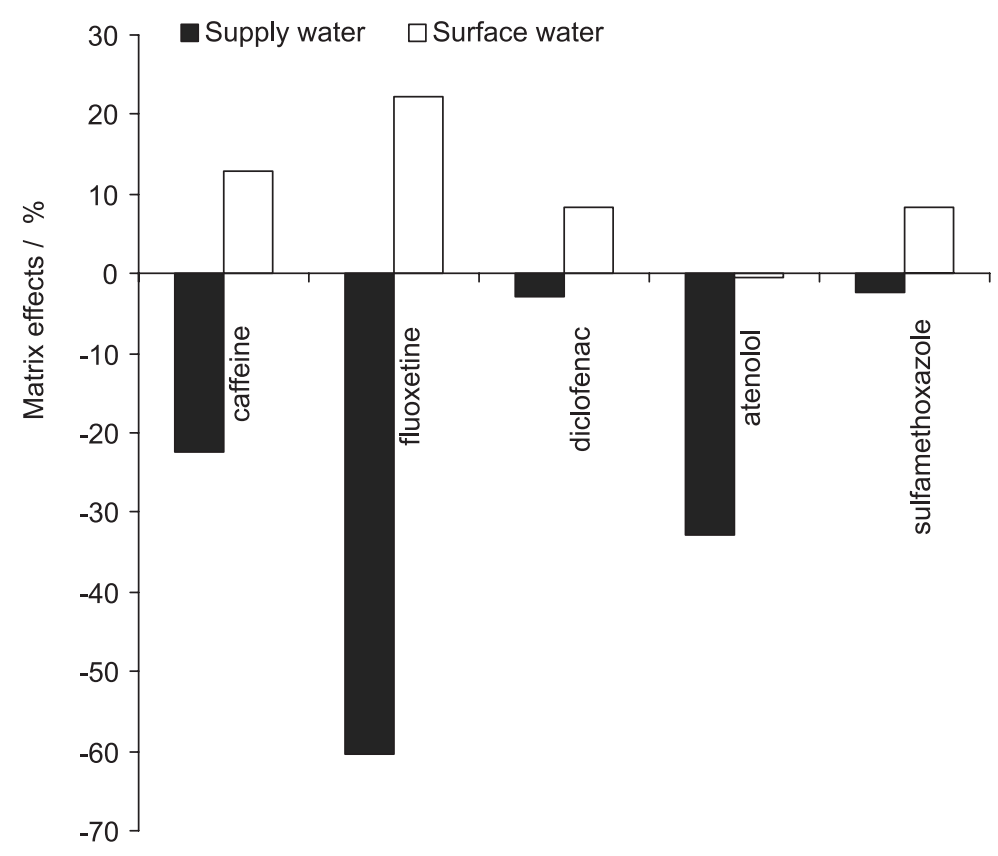

Figure 5. Percentage of matrix effect (ME) for the technique using SPE and LC-APCI-MS/MS for the determination of pharmaceuticals in water.

the extract obtained by SPE and $\mathrm{X}_{2}=$ slope of the curve obtained by injection of the analytical solutions of each pharmaceutical prepared in methanol.

The compound that had a high matrix effect was fluoxetine with a suppression of $-60 \%$ while atenolol had a matrix effect considered medium. For the other compounds, the matrix effect was not significant, as shown in Figure 5.

\section{Method applicability in real samples}

After the optimization and validation, the method was applied to real samples, to evaluate its applicability in the determination of residues of atenolol, caffeine, diclofenac, fluoxetine and sulfamethoxazole pharmaceuticals in surface and drinking water. Water samples were collected at the water treatment plant (CORSAN) and no pharmaceuticals residues were found.

\section{Conclusions}

An analytical methodology for multiclass using SPE and LC-APCI-MS/MS was developed to analyze five selected pharmaceuticals in surface and drinking water samples. The main advantage of the method was the use of MS/MS in the MRM mode which enables the selection of specific fragments of each compound, then allowing a high level of certainty to identify the target compounds.

The results of the method validation were satisfactory. All pharmaceuticals showed good linearity of both instrumental and method with determination coefficients higher than 0.99 . The limits of quantification ranged from 0.053 to $0.53 \mu \mathrm{g} \mathrm{L}-1$, whereas the range of limits of detection was 0.16 to $1.6 \mu \mathrm{g} \mathrm{L}^{-1}$. The recoveries using SPE cartridges with $500 \mathrm{mg}$ Strata-X, obtained for all compounds ranged between 70 to $120 \%$, showing good precision with relative standard deviations below $20 \%$. The method was fast ( $5 \mathrm{~min}$ for analysis), thus reducing the solvent consumption.

It was expected to find residues of the pharmaceutical products since the samples were collected in a water treatment station and there are other articles in the literature which found residues in this matrix. Factors such as excessive rainfall in the region and collection site away from the region where the concentration of drugs was higher (like hospitals) may have influenced the results. The station treatment collect the water of the São Gonçalo Channel (the channel that connects Pelotas City to Rio Grande City), mainly. In this route probably occurs a dilution of the compounds, and this can be one of the reasons for not detecting analytes in samples.

It is noteworthy that only a small number of Brazilian researchers presently aim at the analysis of pharmaceuticals in environmental matrices, this work is expected to draw attention to these compounds that are still little known and less studied as contaminants in the environment and that it can be an encouragement to new researchers.

\section{Acknowledgments}

The authors wish to thank Brazilian agencies: Coordenação de Aperfeiçoamento de Pessoal de Nível 
Superior (CAPES), Fundação de Apoio a Pesquisa do Estado do Rio Grande do Sul (FAPERGS), Conselho Nacional de Desenvolvimento Científico e Tecnológico (CNPq) for the financial support and fellowships, CORSAN for access to the samples and FURG.

\section{References}

1. Pérez, S.; Barceló, D. In Fate of Pharmaceuticals in the Environment and in Water Treatment Systems; Aga, D. S., ed.; $1^{\text {st }}$ ed.; CRC Press: Boca Raton, 2007, ch. 2.

2. Hernández, F.; Sancho, J. V.; Ibáñez, M..; Guerrero, C.; TrAC, Trends Anal. Chem. 2007, 26, 466,

3. Wille, K.; Noppe, H.; Verheyden, K. ; Bussche, J. V.; Wulf, E. D.; Caeter, P. V.; Janssen, C. R.; Brabander, H. F. D.; Vanhaecke, L.; Anal. Bioanal. Chem. 2010, 39, 1799.

4. Shaoa, B.; Chena, D.; Zhanga, J.; Wu, Y.; Sun, C.; J. Chromatogr., A 2009; 1216, 8312.

5. Wu, J.; Qian, X.; Yang, Z.; Zhang, L.; J. Chromatogr., A 2010 , $1217,1471$.

6. Seifrtova, M.; Novakova, L.; Lino, C.; Pena, A.; Solich, P.; Anal. Chim. Acta 2009, 649, 158.

7. Gracia-Lor, E.; Sancho, J. V.; Hernández, F.; J. Chromatogr., A 2010, 1217, 623.

8. Brunton, L. L.; Lazo, J. S.; Park, K. L.; Goodman \& Gilman: As Bases Farmacológicas da Terapêutica, 11a. ed.; Artmed: Porto Alegre, RS, Brasil, 2010.

9. Sun, Z.; Schüssler, W.; Sengl, M.; Niessner, R., Knopp, D.; Anal. Chim. Acta 2008, 620, 73.

10. Silva, P.; Farmacologia, 7a. ed.; Editora Guanabara Koogan: Rio de Janeiro, RJ, Brasil, 2006.

11. Rang, H. P.; Ritter, J. M.; Dale, M. M.; Farmacologia, 6a. ed.; Guanabara Koogan: Rio de Janeiro, RJ, Brasil, 2008.

12. Sabbioni, C.; Bugamelli, F.; Varani, G.; Mercolini, L.; Musenga, A.; Saracino, M. A.; Fanali, S.; Raggi, M. A.; J. Pharm. Biomed. Anal. 2004, 36, 351.
13. Pavlović, D. M.; Babić, S.; Horvat, A. J. M.; Kaštelan-Macan, M.; TrAC, Trends Anal. Chem. 2007, 26, 1064.

14. Kostopoulou, M.; Nikolaou, A.; TrAC, Trends Anal. Chem. 2008, 27, 1026.

15. Rodil, R.; Quintanab, J. B.; López-Mahíaa, P.; MuniateguiLorenzoa, S.; Prada-Rodrígueza, D.; J. Chromatogr., A 2009, 1216, 2966.

16. Ribani, M.; Bottoli, C. B. G.; Collins, C. H.; Jardim, I. C. F. S.; Melo L. F. C.; Quim. Nova 2004, 27, 771.

17. Kasprzyk-Hordern, B.; Dinsdale, R. M.; Guwy, A. J.; Talanta 2008, 74,130.

18. Babić, S.; Pavlović, D. M.; Ašperger, D.; Periša, M.; Zrnčić, M.; Horvat, A. J. M.; Kaštelan-Macan, M.; Anal. Bioanal. Chem. 2010, 398, 1189.

19. Agência Nacional de Vigilância Sanitária (ANVISA); Guia para Validação de Métodos Analíticos e Bioanalíticos, Resolução RE No. 899, Brasil, 2003. http://www.anvisa.gov.br/legis/ resol/2003/re/899_03re.htm.

20. Directorate General for Health \& Consumers - European Commission (DG SANCO); Method Validation and Quality Control Procedures for Pesticide Analysis in Food and Seeds, Doc. No. SANCO/106842009, Europe, 2009, http://ec.europa. eu/food/plant/protection/resources/qualcontrol_en.pdf accessed in December 2010.

21. Kruve, A.; Leit, I.; Herodes, K.; Anal. Chim. Acta 2009, 651, 75.

22. Marín, J. M.; Gracia-Lor, E.; Sancho, J. V.; López, F. J.; Hernández, F.; J. Chromatogr., A 2009, 1216, 1411.

23. Gosetti, F.; Mazzucco, E.; Zampieri, D.; Gennaro, M. C.; J. Chromatogr., A 2010, 1217, 3930.

24. Economou, A.; Botitsi, H.; Antoniou, S.; Tsipi, D.; J. Chromatogr., A 2009, 1216, 5861.

Submitted: February 7, 2011

Published online: August 16, 2011 